\title{
Por uma superação da relação falaciosa entre turismo e desenvolvimento local: uma análise do turismo em comunidades à luz da gestão social
}

\author{
Overcoming the Misleading Relationship between Tourism and Local Development: An Analysis of Tourism in a Pacific Community in \\ Light of Social Management
}

\section{Resumo}

A partir da década de 1990, as comunidades do Rio de Janeiro passaram a se destacar como um atrativo turístico. Como ressalta Medeiros (2010), a comunidade como produto turístico é, hoje, um fato. Cabe, agora, refletir como essa atividade pode ser explorada de modo a trazer benefícios aos moradores das comunidades. Nesse sentido, assumindo a importância da participação social para a superação de uma relação falaciosa entre turismo e desenvolvimento, o artigo tem como objetivo analisar 0 desenvolvimento da atividade turística em uma comunidade pacificada, a partir da perspectiva da gestão social. Foram realizadas entrevistas com moradores, guias de turismo e policiais. Tais entrevistas foram analisadas por meio de categorias propostas por Tenório et al. (2008) para avaliação de processos decisórios participativos, quais sejam inclusão, pluralismo e bem comum. Observou-se, com base na análise, que a inserção dos moradores no desenvolvimento de atividades turísticas é dificultada, levando a avanços apenas em aspectos econômicos. 0 crescimento econômico é, porém, insuficiente para a geração de transformações sociais mais amplas, as quais também são abarcadas pelo conceito de desenvolvimento, conforme mostrou Furtado (2000).

Palavras-chave: turismo; desenvolvimento local; comunidade; pacificação; gestão social.

Fernando Guilherme Tenório - fernando.tenorio@fgv.br

Doutor em Engenharia de Produção pela COPPE/UFRJ. Escola Brasileira de Administração Pública e de Empresas da Fundação Getulio Vargas (EBAPE/FGV).

Vanessa Brulon - vanessabrulon@gmail.com

Mestre em Administração Pública pela EBAPE/FGV e doutoranda em Administração pela EBAPE/FGV. Escola Brasileira de Administração Pública e de Empresas da Fundação Getulio Vargas (EBAPE/FGV).

Lucas Zarconi - lucas.zarconi@gmail.com

Graduação em Administração pela EBAPE/FGVe mestrando em Administração pela EBAPE/FGV. Escola Brasileira de Administração Pública e de Empresas da Fundação Getulio Vargas (EBAPE/FGV).

Em conformidade com o Manual de Boas Práticas da Anpad, este artigo foi submetido aos mesmos critérios de avaliação adotados para todos os textos dos Cadernos Gestão Pública e Cidadania, tendo sido aprovado após exame pelo critério double blind peer review.

Artigo submetido no dia 06 de outubro de 2012 e aprovado em 19 de março de 2013 


\section{Abstract}

In the 1990s, the communities of Rio de Janeiro began to stand out as tourist attractions. As noted by Medeiros (2010), the community as a tourism product is now a fact. Indeed, it is now important to reflect on how this activity can be exploited to benefit community residents. In this sense, assuming the importance of social participation for overcoming a misleading relationship between tourism and development, the paper aims to analyze the development of tourism in a peaceful community, from the perspective of social management. Interviews were conducted with residents, tour guides and police. These interviews were analyzed according to categories proposed by Tenorio et al (2008) for evaluating participatory decision-making processes, namely, inclusiveness, pluralism and the common good. The analysis indicated that the insertion of residents in the development of tourist activities is hampered, leading to advances in economics aspects only. Economic growth is, however, insufficient to generate broader social transformations, which are also involved in the concept of development, as shown by Furtado (2000).

Key-words: Tourism, local development, community, peace and social management.

\section{Introdução}

A desigualdade social, que marca a realidade de muitos países no contexto contemporâneo, manifesta-se no Brasil principalmente por meio do fenômeno urbano que leva à formação das chamadas "favelas". Caracterizadas como espaços em que os indivíduos vivem em condições precárias, malservidos pela infraestrutura e serviços urbanos, e localizadas em áreas ambientalmente frágeis, essas comunidades têm sido consideradas um dos principais problemas urbanos atuais (MARICATO, 2001). Esse fenômeno ganha destaque na cidade do Rio de Janeiro, que tem a ela atrelada uma variedade de dicotomias que expressam sua fragmentação. "Morro" e "asfalto", "pobres" e "ricos" convivem lado a lado em um território em que a ação antrópica gerou problemas que se acumularam, compondo um contexto de precariedade espacial.

Como lembra Martins (2001), a atribuição do nome "favela" para os aglomerados humanos pobres das grandes metrópoles brasileiras é um legado da guerra de Canudos. O autor explica que, após a referida guerra, os soldados passaram a habitar o morro da Providência, na cidade do Rio de Janeiro, e o denominaram "favela" como uma associação à elevação topográfica baiana onde predominava uma vegetação chamada "favela". Mais tarde, o termo "comunidade" passou a ser adotado como uma forma politicamente correta de se referir às favelas. Embora o termo comunidade, em seu sentido geral, conforme definido do dicionário Aurélio, seja assumido como um "agrupamento social que se caracteriza por acentuada coesão baseada no consenso espontâneo dos indivíduos que o constituem," o senso comum passou a adotá-lo como sinônimo de "favela", para evitar o sentido pejorativo que o termo passou a carregar.

A cidade do Rio de Janeiro, ainda que fragmentada e marcada pela formação das "favelas" ou "comunidades", sempre despertou o interesse de turistas, principalmente por seus atrativos relacionados à beleza natural. Entretanto, a partir da década de 1990, o outro lado desse cenário dicotômico passou a se destacar como um atrativo turístico. As comunidades da cidade do Rio de Janeiro tornaram-se um ponto turístico equiparável ao Pão de Açúcar e ao Cristo Redentor, no que diz respeito à quantidade de turistas que recebem para visitação. Com o processo de pacificação das comunidades da cidade, a partir de 2008, o turismo em comunidades ganhou força, com a consolidação de um novo produto: a "favela pacificada". Merece destaque, nesse sentido, a comunidade Santa 
Marta, pioneira no processo de pacificação.

A criação desse novo produto turístico associado à pobreza já foi objeto de estudo de trabalhos anteriores (MEDEIROS, 2006; MEDEIROS, 2007). Moraes (2010), por exemplo, analisou a implementação do Projeto Turismo no Museu de Favela, localizado na comunidade do Cantagalo. Serson e Pires (2008) propuseram-se a investigar as atividades turísticas na favela da Rocinha, tendo como foco de pesquisa as expectativas e experiências dos turistas. Outros trabalhos adotaram como foco de pesquisa as representações das favelas. Menezes (2007) buscou entender as representações das favelas para os turistas por meio da análise de fotografias que levam delas. Já Godoy e Luna (2012) analisaram filmes, como uma forma de investigar o efeito das imagens cinematográficas sobre favelas no imaginário, tendo em vista que essas imagens podem influenciar a criação do produto "turismo em favela".

Como destaca Medeiros (2010), a comunidade como produto turístico é, hoje, um fato. Constitui-se, segundo a autora, como um negócio rentável para as agências de turismo, um destino que atrai estrangeiros e uma realidade que já faz parte do cotidiano dos moradores. Esse fenômeno tende a se disseminar, em decorrência dos eventos esportivos que serão sediados na cidade nos próximos anos. Como um fato consumado, cabe, agora, refletir como essa atividade pode ser explorada de modo a trazer benefícios aos moradores das comunidades, aqueles que mais precisam e merecem um retorno.

A desejada compensação para os membros da comunidade pode ser obtido por meio da relação entre turismo e desenvolvimento local. Parece haver consenso, na literatura especializada, de que o turismo é uma via para $o$ alcance do desenvolvimento local, uma vez que traz benefícios socioeconômicos para a localidade em que a atividade turística se dá. Entretanto, Holanda e Vieira (2003) chamam atenção para a falácia da relação direta entre os dois conceitos. $\mathrm{Na}$ visão dos autores, para que o turismo leve ao desenvolvimento, a participação da comunidade local é condição necessária. Na mesma direção, Tenório (2007) ressalta a importância da cidadania para o processo de desenvolvimento local. É nesse sentido que ganha destaque a noção de gestão social, caracterizada pelo estabelecimento de um diálogo entre diferentes atores, que expõem suas argumentações por meio da razão, alcançando acordos por meio da comunicação (TENÓRIO, 2008). A gestão social, assim entendida, é destacada como condição necessária para que a relação entre turismo e desenvolvimento local efetivamente se dê.

Ao assumir a importância da participação social para a superação de uma relação falaciosa entre turismo e desenvolvimento, e no intuito de discutir os possíveis retornos para os membros da comunidade, o artigo tem como objetivo analisar o desenvolvimento da atividade turística em uma comunidade pacificada, a partir da perspectiva da gestão social.

\section{PorumaSuperaçãodaRelaçãoFalaciosa entre Turismo e Desenvolvimento Local}

Para que o turismo em comunidades venha a trazer benefícios para seus moradores, é importante que se discuta a relação entre turismo e desenvolvimento local como uma possível via. O estabelecimento de uma relação direta entre os dois conceitos, entretanto, pode ser questionado. A gestão social apresentase, assim, como uma forma de superar essa falácia (HOLANDA; VIEIRA, 2003; 
TENÓRIO, 2007).

\subsection{O turismo em comunidades}

O conceito de turismo sofreu alterações ao longo do tempo. A definição inicial, que o relacionava a viagens para locais distantes 50 milhas da residência, com duração de mais de 24 horas, sem o exercício de ocupação remunerada (LAGE; MILONE, 2000), passou a ser debatida, tendo em vista sua ampliação. Como consequência do debate, hoje já se admite que delimitar uma definição específica de turismo é impossível, podendo-se afirmar apenas que é uma atividade socioeconômica, pois gera a produção de bens e serviços, suprindo necessidades básicas e secundárias dos turistas (LAGE; MILONE, 2000).

Segundo Lage e Milone (2000), o turismo traz grande impacto para a economia de um país ou região e é de grande importância o estudo, acompanhamento e desenvolvimento dessa atividade. Tal impacto pode ser ilustrado pelos dados do IBGE (2010), que revelam que, em 2007, as atividades turísticas geraram renda de 82,7 bilhões de reais e respondiam por $5,6 \%$ do setor de serviços, contando com 5,9 milhões de postos de trabalho.

O Brasil, em 2010, recebeu 5,1 milhões de turistas estrangeiros, o que gerou 5,9 bilhões de dólares em receita cambial (MINISTÉRIO DO TURISMO, 2011). Desse total, o estado do Rio de Janeiro, no ano de 2010, recebeu 980 mil turistas estrangeiros e contava com 1.522 agências cadastradas no Ministério do Turismo e 87 mil leitos de hospedagem (MINISTÉRIO DO TURISMO, 2011). Além disso, a cidade do Rio de Janeiro destaca-se hoje como a cidade mais visitada do País.

A grande quantidade de turistas que visitam a cidade do Rio de Janeiro, expressa nos dados acima, vem em busca, principalmente, de seus atrativos naturais, que fazem da cidade uma das mais belas do mundo. Mas a pobreza da cidade, nos últimos anos, também vem atraindo os turistas (MEDEIROS, 2009). Segundo Medeiros (2006), é a partir da década de 1990 que a prática de atividades turísticas nas chamadas "favelas" torna-se massiva.

Conforme Denaldi (2005), nos principais centros metropolitanos do País, de 20 a $40 \%$ da população total residem em favelas. O censo demográfico do IBGE de 2010 apontou a existência de mais de 11 milhões de brasileiros residentes em favelas. Maricato (2001) explica que o termo "favela" refere-se a regiões marcadas por uma situação ilegal de ocupação do solo, na qual o morador não tem direito sobre a terra que ocupa, podendo ser despejado a qualquer momento. A autora as caracteriza como regiões sujeitas à exclusão urbana, já que são malservidas pela infraestrutura e serviços urbanos, como os de água, esgoto ou transporte. Outro problema dessas comunidades, levantado pela autora, diz respeito à sua localização em áreas ambientalmente frágeis, como encostas íngremes ou beira de córregos, sujeitas a desmoronamento.

Embora tenham surgido como forma de solução imediata para um problema urbano de habitação da população mais pobre, em um cenário de elevação de preços dos solos, essas comunidades tornaramse uma das principais questões urbanas, na medida em que foram se expandindo. Com sua ampliação, elas passaram a ser enxergadas como um "problema" social que precisava ser combatido (OLIVEIRA, 1985). Segundo Valladares (2000), no início do século XX, o "problema das favelas" passou a ser discutido por jornalistas, médicos e 
engenheiros que demonstravam preocupação com o futuro da população, e tornou-se alvo de ações do governo.

No Brasil, merece destaque a cidade do Rio de Janeiro, local em que foi formulado o maior número de políticas governamentais voltadas para as comunidades (VALLADARES; FIGUEIREDO, 1983). Como mostrou Valladares (2000), a primeira comunidade surgiu no Rio de Janeiro, no Morro da Providência, no fim do século XIX, e, desde então, essa forma de aglomeração urbana disseminou-se pela cidade. Nesse sentido, o Rio de Janeiro acabou se tornando o principal objeto de análise da maioria dos trabalhos que discutem a origem e a expansão das comunidades (COSTA; NASCIMENTO, 2005).

Por constituírem-se em um espaço marcado por condições de vida precárias, a consolidação das comunidades pobres da cidade do Rio de Janeiro como um ponto turístico frequentemente visitado por turistas estrangeiros chama atenção. Essa questão foi investigada por Medeiros (2006), que defende a associação desse fenômeno à popularidade internacional dos reality tour ("tours sociais" ou "tours sombrios"), bem como à circulação global de produtos que representam o "mundo exótico da favela". O turismo em comunidades é considerado um tipo de "tour social", que se caracteriza por ter como destino uma região com desvantagem econômica, proporcionando uma experiência de autenticidade e a sensação de ser um bom cidadão (MEDEIROS, 2007). O processo de pacificação pelo qual essas comunidades passaram a partir de 2008 também é identificado como um fator intensificador do fenômeno.

Medeiros (2009) chama atenção para o fato de que $99 \%$ dos turistas atraídos por esses elementos são estrangeiros. Embora os habitantes das comunidades se vejam diante de turistas estrangeiros, o que implica, na maior parte das vezes, uma barreira linguística, Medeiros (2007) defende que os moradores não são passivos, no que diz respeito ao processo de desenvolvimento de atividades turísticas nas comunidades. O olhar investigativo que, muitas vezes, lançam ao turista marca, na visão da autora, seu papel ativo.

Segundo Medeiros (2010), quer se goste ou não, o turismo em comunidades é, hoje, um fato que marca a realidade da cidade do Rio de Janeiro. Nesse sentido, cabe investigar como essas atividades turísticas podem ser exploradas de modo a trazer um retorno para os moradores das comunidades. A relação entre turismo e desenvolvimento local pode ser um meio pelo qual esses benefícios talvez sejam alcançados pelos membros das comunidades.

\subsection{Por uma relação efetiva entre turismo e desenvolvimento local}

O turismo intensificou-se com a evolução das tecnologias de comunicação e de meios de transporte, crescendo de modo a ser, hoje, pensado não apenas como uma atividade de lazer, mas como uma atividade que ocupa importante papel social, político e econômico, sendo, para alguns países, o motor de seu desenvolvimento (BATISTA, 2003).

Segunda Holanda e Vieira (2003), é muito frequente, na literatura especializada, a defesa da existência de uma relação entre turismo e desenvolvimento local. Essa ideia parece estar associada, conforme os autores, à geração de renda, empregos diretos e indiretos e à consequente melhora da qualidade de vida da localidade.

Cunha(1997), por exemplo, apresenta algumas razões pelas quais o turismo pode 
contribuir para o desenvolvimento local. Em primeiro lugar, para o autor, como o turismo é função das características locais, para as regiões que têm potencial, é a atividade turística que melhor pode desenvolver esses recursos locais. Além disso, o autor explica que, quando um turista consome produtos produzidos localmente, ocorre uma transferência de rendimentos que poderia não existir caso não houvesse a atividade. Pode-se afirmar, também, segundo Cunha (1997), que a atividade turística demanda e justifica investimentos das iniciativas privada e pública em infraestrutura, equipamento, capacitação, que acabam por beneficiar a população local e possibilitar a instalação de outras atividades. Ainda, conforme o autor, o turismo desenvolve a produção local, possibilitando o equilíbrio das desigualdades de uma região.

Entretanto, Holanda e Vieira (2003) chamam atenção para o papel marginalizado que ocupam as comunidades locais, podendo as expressões locais e regionais ficar de fora das atividades turísticas da região. Para os autores, é importante a existência de "projetos integrados em nível local que envolvam os mais variados atores socioeconômicos para dar-lhe sustentação como vetor de desenvolvimento local" (HOLANDA; VIEIRA, 2003, p. 282). Conforme os autores, para que o turismo leve ao desenvolvimento local, é crucial que haja uma gestão participativa, que articule o poder público, a iniciativa privada e a sociedade civil. Quando isso não acontece, a relação entre turismo e desenvolvimento torna-se falaciosa. Indo ao encontro de Holanda e Vieira (2003), Sousa (2006) defende que, além de se conhecerem os recursos da região, é de crucial importância o envolvimento da população no planejamento e implementação do turismo.

Para que o turismo, então, promova o desenvolvimento de maneira mais significativa e com o menor número de impactos negativos, deve contemplar as relações entre os atores privados, públicos e a população. Essa pluralidade é destacada por Oliveira (2001, p. 168):

O planejamento e a operação do turismo devem ser intersetoriais e integrados, envolvendo várias organizações governamentais, empresas privadas, grupos de cidadãos e indivíduos, permitindo deste modo obter o maior número possível de benefícios.

Os autores ressaltam, assim, a importância da participação da comunidade local, bem como da pluralidade de atores envolvidos nas atividades turísticas, para que essa relação entre turismo e desenvolvimento local efetivamente se dê. Dessa maneira, apontam para a gestão social como uma forma de superação da relação falaciosa entre turismo e desenvolvimento local.

\subsection{A importância da gestão social para 0 desenvolvimento local}

Para que o desenvolvimento de atividades turísticas em uma dada localidade leve efetivamente ao desenvolvimento local, a noção de gestão social é relevante. A importância da gestão social para que o desenvolvimento local se dê é marcada em trabalhos anteriores, como em Tenório (2007), Tenório (2008) e Holanda e Vieira (2003). A noção de gestão social trabalhada por esses autores tem origem nos pressupostos do agir comunicativo, conforme proposto por Habermas (2002).

Representante da segunda geração da Escola de Frankfurt, Habermas (2002) leva adiante a crítica ao predomínio da 
racionalidade instrumental, mas consegue enxergar uma saída por meio de uma ação social do tipo comunicativa. Com o desenvolvimento da Teoria da Ação Comunicativa, o filósofo alemão Jürgen Habermas propõe outro tipo de racionalidade, a comunicativa, como alternativa à racionalidade instrumental.

$\mathrm{Na}$ Teoria da Ação Comunicativa habermasiana, a comunicação entre participantes de uma mesma comunidade torna-se central e passa a ser entendida como o princípio ordenador da vida humana associada (VIZEU, 2005). Segundo Tenório (2002), a racionalidade comunicativa proposta por Habermas promove a mediação entre a teoria e a prática, por meio do diálogo que se estabelece entre os agentes sociais do processo. Assim, como explica Vizeu (2005), a racionalidade comunicativa dá-se por meio do uso de argumentos válidos, pautados na razão. Nas palavras de Habermas (2002, p. 51):

Também no agir comunicativo partimos da ideia de que todos os participantes são atores capazes de se justificarem. De fato, pertence à autocompreensão dos sujeitos agindo comunicativamente que assumam posições racionalmente motivadas para as exigências de validez; os atores supõem reciprocamente que de fato agem a partir de razões justificadas.

Por meio da ação comunicativa assim pensada, Habermas defende a ideia da negociação da liberdade e da emancipação de cada indivíduo no todo societário (FREITAG, 1995). É nesse sentido que Habermas (2002) traz o conceito de esfera pública, entendida como uma estrutura comunicacional onde ecoam os problemas do sistema político. É o espaço social gerado no agir comunicativo (HABERMAS, 1997). Mas o autor chama atenção para o fato de que a esfera pública não deve se limitar a identificar tais problemas, mas também problematizá-los de modo que sejam incorporados no complexo parlamentar.

Orientada por uma racionalidade comunicativa, a gestão social dáse por meio de um acordo alcançado comunicativamente entre os diferentes atores, que expõem suas argumentações por meio da razão (TENÓRIO, 2008). Assim, conforme explica Tenório (2008), só existe verdade no processo de gestão social se todos os participantes admitem sua validade.

Entretanto, Tenório (2008) chama atenção para o fato de que a gestão social, no contexto contemporâneo, tem se aproximado da gestão estratégica, pautando-se pela lógica do mercado, em detrimento de questões de natureza social. É nesse sentido que se torna ainda mais relevante que as diferenças entre as duas perspectivas sejam marcadas e apontadas, tendo em vista a retomada de uma gestão social livre de contaminações.

A gestão estratégica pode ser entendida como "um tipo de ação social utilitarista, fundada no cálculo de meios e fins e implementada através da interação de duas ou mais pessoas na qual uma delas tem autoridade formal sobre a(s) outra(s)" (TENÓRIO, 2008, p. 23). Dessa forma, a gestão estratégica produz o comportamento tecnocrático, por meio da junção de competência técnica com atribuição hierárquica, conforme mostrou Tenório (2008).

A gestão social, por sua vez, opõese à gestão estratégica na medida em que "tenta substituir a gestão tecnoburocrática, monológica, por um gerenciamento mais participativo, dialógico, no qual o processo decisório é exercido por meio de diferentes 
sujeitos sociais" (TENÓRIO, 2008, p. 25).

No intuito de enfatizar as diferenças entre as duas perspectivas, Tenório (2008, p. 27) lembra que, "enquanto a gestão estratégica procura objetivar o 'adversário' através da esfera privada, a gestão social deve atender, por meio da esfera pública, o bem comum da sociedade". Indo ao encontro de Tenório (2008), Pinho (2010) defende que a gestão social afasta-se de outras formas de gestão convencionais, por sua finalidade não lucrativa, bem como pelo fato de mobilizar recursos que não estão restritos aos financeiros.

Tenório (2008) explica que a gestão social tem sido discutida, nos últimos anos, como uma forma de destacar a importância das questões sociais, no que diz respeito tanto à administração pública quanto à administração privada. Boullosa e Schommer (2010) destacam o fato de que a gestão social propõe um novo modelo de relações entre Estado e sociedade, no qual o Estado revê sua posição de primazia na condução de processos de transformação social.

Marcando as especificidades da gestão social, que a distanciam da gestão estratégica, Oliveira, Cançado e Pereira (2010) destacam três de suas características, que podem ser consideradas centrais. A primeira delas, segundo os autores, é a tomada de decisão coletiva, baseada no entendimento e na argumentação, sem que haja qualquer forma de coerção. Em seguida, os autores mencionam a transparência, tendo em vista que, para que o processo decisório se dê por meio da comunicação e do entendimento, é preciso que as informações estejam disponíveis a todos. Por fim, tais estudiosos ressaltam a emancipação como o resultado da gestão social, já que a participação no processo de tomada de decisão leva ao crescimento e ao amadurecimento dos atores, que passam a se enxergar como cidadãos participantes de uma esfera pública.

A importância da gestão social para o processo de desenvolvimento é enfatizada principalmente quando se deixa de pensar no desenvolvimento como sinônimo de crescimento econômico. Ao longo do seu processo de expansão, a teoria do desenvolvimento sofreu importantes transformações, e o papel do crescimento econômico para o desenvolvimento, superestimado em um período inicial, passou a ser entendido como um critério necessário, mas longe de ser suficiente (SACHS, 2005). Nesse percurso, a noção de desenvolvimento foi aumentando em complexidade, e, à dimensão econômica, foram acrescentadas dimensões sociais, políticas, culturais, éticas, ambientais e territoriais, conforme mostrou Sachs (2005).

Em uma tentativa de se opor ao pensamento dominante, alguns autores passaram a tratar o conceito de desenvolvimento a partir de uma perspectiva mais abrangente, ressaltando a importância de aspectos substantivos e culturais. Importante autor latino-americano a abordar a temática do desenvolvimento, Furtado (2000), defensor dessa visão mais ampla, entende o conceito em dois sentidos distintos: o primeiro, em relação à evolução de um sistema social de produção, e o segundo, relacionado com o grau de satisfação das necessidades humanas.

Ao definir desenvolvimento a partir de seus dois sentidos, Furtado (2000, p. 22) ressalta a importância de se pensar nos fins substantivos desejados ao se discutir o conceito, sem que se deixe guiar apenas pela lógica dos meios, imposta do exterior. Para o autor, o desenvolvimento futuro deve abrir espaço para a realização das potencialidades 
da cultura local e reencontro com o gênio criativo dessa cultura. $O$ autor reforça, assim, a importância da preservação de uma identidade cultural e da liberação das forças criativas da sociedade. Daí a importância do enriquecimento cultural e da participação social para o processo de desenvolvimento.

No contexto contemporâneo, merece destaque o pensamento de Sachs (2005), que defende que o conceito de desenvolvimento deve ser discutido com base nas dimensões que, no momento, podem ser consideradas as mais pertinentes. Nesse sentido, para o autor, "convém acompanhar o conceito de desenvolvimento dos três epítetos seguintes: (socialmente) includente, (ambientalmente) sustentável, (economicamente) sustentado" (SACHS, 2005, p. 156). Propõe, assim, que se busque um "novo desenvolvimento", interligado à identidade nacional.

Para pensar essa proposta de desenvolvimento no contexto de comunidades, um novo conceito de desenvolvimento, o "desenvolvimento local", foi estabelecido e é, hoje, um dos conceitos de desenvolvimento mais populares (BOISIER, 2000). Segundo Buarque (2002, p. 25), esse conceito é comumente definido como "um processo endógeno de mudança, que leva ao dinamismo econômico e à melhoria da qualidade de vida da população em pequenas unidades territoriais e agrupamentos humanos.' Martins (2002) vai além e aponta, como o verdadeiro diferencial da noção de desenvolvimento local, o papel de agente que atribui à comunidade, destacando a questão da participação como central nesse processo.

Ao pensar na perspectiva do desenvolvimento local, em sua visão, entendido como "um processo centrado em um território concreto no qual os protagonistas são uma pluralidade de atores que ocupam determinadas posições no espaço social [...]"
(TENÓRIO, 2007, p. 105), Tenório destaca a importância da cidadania deliberativa, que significa que "a legitimidade das decisões políticas deve ter origem em processos de discussão, orientados pelos princípios da inclusão, do pluralismo, da igualdade participativa, da autonomia e do bem comum" (TENÓRIO, 2007, p. 105).

Segundo Tenório (2007), é por meio da integração desses dois conceitos que se torna possível a mudança para uma gestão descentralizada, na qual há a interação entre os diferentes grupos que compõem a sociedade local e o poder público, trazendo benefícios para a comunidade. Entretanto, 0 autor ressalta que, para que seja possível um desenvolvimento com cidadania, é preciso que haja participação, ou seja, o privilégio de ações concertadas entre sociedade civil, mercado e Estado.

Para Tenório (2008), as ações locais de desenvolvimento devem se dar por meio da facilitação do poder público, que não deve manter o monopólio das ações. Na visão do autor, as ações de desenvolvimento só terão eficácia se o poder público se colocar como apenas um dos agentes envolvidos e levar em conta a cultura local, possibilitando um projeto que seja apropriado pela sociedade. A participação efetiva dos diferentes grupos de interesse e das comunidades nas decisões torna-se um objetivo central (TENÓRIO, 2008).

Diante da importância da gestão social para o desenvolvimento, Tenório et al. (2008) propõem, com base em uma densa discussão teórica, alguns critérios para a avaliação de processos decisórios participativos deliberativos. Segundo os autores, "a legitimidade das decisões políticas deve ter origem em processos de discussão, orientados pelos princípios da inclusão, do pluralismo, da igualdade 
participativa, da autonomia e do bem comum" (TENÓRIO et al., 2008, p. 9).

Com base na obra de Tenório et al. (2008), Villela (2012) propõe-se a aprofundar ainda mais a discussão em torno dos critérios para a avaliação de processos decisórios participativos deliberativos propostos pelos autores. Villela (2012, p. 40) esclarece que os processos de discussão, definidos por Tenório et al. (2008) como a discussão de problemas por meio da autoridade negociada na esfera pública, com igualdade de direitos entre os atores sociais envolvidos, "constitui o diálogo que verbaliza a compreensão que cada um tem do objeto em análise." A inclusão, critério proposto como a incorporação de novos atores individuais ou coletivos (TENÓRIO et al., 2008), leva em conta, segundo Villela (2012), de que forma a situação em questão dá "voz" aos atores locais. No que diz respeito ao pluralismo, definido por Tenório et al. (2008) como a multiplicidade de atores envolvidos nos processos de tomada de decisão, Villela (2012) esclarece que esse critério tem por foco a descentralização. A igualdade participativa, ou seja, a igualdade de participação nos processos decisórios (TENÓRIO et al., 2008), justifica-se, segundo Villela (2012, p. 41), "pela avaliação da isonomia de oportunidades." Por sua vez, a autonomia, entendida como a apropriação do poder decisório pelos atores (TENÓRIO et al., 2008), justifica-se "pela identificação da capacidade de avaliação e resolução de problemas locais pelas próprias comunidades" (VILLELA, 2012, p. 41). Por fim, o bem comum, definido por Tenório et al. (2008, p. 11) como "bem-estar social alcançado através da prática republicana", é apontado por Villela (2012) como um critério que se justifica pela identificação de seus efeitos na melhoria das condições de vida das comunidades.

Vale ressaltar que os critérios de análise acima explicitados já foram utilizados como escopo metodológico de alguns trabalhos. Melo (2012), por exemplo, pautou-se em tais critérios para analisar a relação cotidiana entre a sociedade civil e o poder público tendo em vista o desenvolvimento local, na microrregião de Garanhuns (PE). Pode-se citar, ainda, estudo semelhante realizado por Faria e Dias (2012) na microrregião de Lavras (MG).

Evidencia-se, assim, a importância da participação social para a noção de desenvolvimento, presente no pensamento de autores como Furtado (1984; 2000), Sachs (2005) e Tenório (2007; 2008). Diante da importância de se ter um desenvolvimento interligado à identidade cultural, que abra espaço para a expressão das potencialidades da cultura local e que esteja atrelado à noção de cidadania, a gestão social precisa se fazer presente nas atividades turísticas para que se alcance o tão desejado projeto de desenvolvimento.

\section{Método de Pesquisa}

A pesquisa aqui desenvolvidafaz parte de um projeto mais amplo, intitulado "Modelagem de Plano Estratégico de Ações para Estimular - Turismo em Comunidades Pacificadas", que surgiu a partir de uma demanda do Ministério do Turismo. Para atender ao objetivo, deste trabalho específico, de analisar o desenvolvimento da atividade turística em uma comunidade pacificada, a partir da perspectiva da gestão social, foram entrevistados moradores, líderes comunitários, comerciantes locais, guias de turismo e policias que atuam na comunidade Santa Marta, com um total de 25 entrevistas semiestruturadas de, em média, uma hora e meia de duração. Representantes do governo não foram entrevistados e, por isso, 
seu posicionamento não aparece de maneira direta em nossas análises. Para determinar o número de entrevistados, foi utilizado o critério de saturação. As entrevistas foram realizadas durante o primeiro semestre de 2011, e os entrevistados foram selecionados com base na observação de indivíduos que tinham algum envolvimento com as atividades turísticas na comunidade, bem como por meio de indicações. A comunidade Santa Marta foi selecionada como campo de estudo por ser, atualmente, a comunidade com maior desenvolvimento de atividades turísticas na cidade do Rio de Janeiro, provavelmente em decorrência de seu pioneirismo no processo de pacificação.

As entrevistas semiestruturadas foram integralmente transcritas, e foi realizada a análise interpretativa dos dados baseada em categorias preestabelecidas e na base teórica revisada. $O$ tratamento e a análise dos dados se deram com base em algumas categorias de análise, bem como em seus respectivos critérios, propostos por Tenório et al. (2008), como critérios para a análise de processos decisórios participativos deliberativos. As categorias, conforme propostas pelos autores, foram selecionadas de acordo com a aplicabilidade ao contexto das atividades turísticas investigadas. Principalmente devido ao fato de o desenvolvimento dessas atividades ser recente na comunidade Santa Marta, algumas categorias não puderam ser analisadas, devido à necessidade de um período mais longo de consolidação do turismo. De acordo com Tenório et al. (2008, p. 15), "os critérios de avaliação de participação cidadã elaborados no artigo podem contribuir para a avaliação de diversas modalidades de ações de cidadania deliberativa".

De posse da transcrição integral das entrevistas, operou-se a busca e sistematização dos fragmentos relevantes para a argumentação, de acordo com os critérios de cada categoria. As categorias e seus critérios, conforme propostos por Tenório et al. (2008), são apresentados na Tabela 1, a seguir:

Tabela 1 - Critérios para a análise de processos decisórios participativos deliberativos.

\begin{tabular}{|c|c|}
\hline is & Critérios \\
\hline \multirow{3}{*}{$\begin{array}{l}\text { Inclusão: incorporação de } \\
\text { atores individuais e coletivos } \\
\text { anteriormente excluídos dos } \\
\text { espaços decisórios. }\end{array}$} & $\begin{array}{l}\text { Abertura dos espaços de decisão: processos, mecanismos, instituições } \\
\text { que favorecem a articulação dos interesses dos cidadãos ou dos grupos, } \\
\text { dando uma chance igual a todos de participação na tomada de decisão. }\end{array}$ \\
\hline & $\begin{array}{l}\text { Aceitação social, política e técnica: reconhecimento pelos atores da } \\
\text { necessidade de uma metodologia participativa, tanto no âmbito social, } \\
\text { quanto no político e no técnico. }\end{array}$ \\
\hline & $\begin{array}{l}\text { Valorização cidadã: valorização por parte da cidadania sobre a } \\
\text { relevância da sua participação. }\end{array}$ \\
\hline \multirow{2}{*}{$\begin{array}{l}\text { Pluralismo: multiplicidade } \\
\text { de atores (poder público, } \\
\text { mercado e sociedade civil) } \\
\text { que, a partir de seus } \\
\text { diferentes pontos de vista, } \\
\text { estão envolvidos no processo } \\
\text { de tomada de decisão. }\end{array}$} & $\begin{array}{l}\text { Participação de diferentes atores: atuação de associações, movimentos } \\
\text { e organizações, bem como cidadãos não organizados, envolvidos no } \\
\text { processo deliberativo. }\end{array}$ \\
\hline & $\begin{array}{l}\text { Perfil dos atores: características dos atores em relação as suas } \\
\text { experiências em processos democráticos de participação. }\end{array}$ \\
\hline \multirow{2}{*}{$\begin{array}{l}\text { Bem comum: bem-estar } \\
\text { social alcançado através da } \\
\text { prática republicana. }\end{array}$} & $\begin{array}{l}\text { Objetivos alcançados: relação entre os objetivos planejados e os } \\
\text { realizados. }\end{array}$ \\
\hline & $\begin{array}{l}\text { Aprovação cidadã dos resultados: avaliação positiva dos atores sobre } \\
\text { os resultados alcançados. }\end{array}$ \\
\hline
\end{tabular}

Fonte: Adaptado de Tenório et al. (2008). 


\section{A Comunidade Santa Marta}

No coração da Zona Sul, a comunidade Santa Marta encontra-se no bairro de Botafogo, às margens de uma das maiores e mais movimentadas avenidas do bairro, a São Clemente. Por estar localizada na Zona Sul da cidade, região que abriga grande parte dos pontos turísticos do Rio de Janeiro, quem sobe as escadarias ou 0 plano inclinado, inaugurado em 2009, pode avistar muitos cartões-postais da cidade.

Dona Marta é o nome do morro onde se encontram o mirante, a floresta e a comunidade. $O$ que se denomina comunidade Santa Marta é a população que habita esse morro. Com aproximadamente 4.700 moradores, a comunidade Santa Marta conta com muitos atrativos turísticos, que já a fizeram, muitas vezes, objeto de destaque na mídia. Além da famosa vista e do trabalho de ONGs que costumam ser visitadas, a comunidade possui a conhecida "Laje do Michel Jackson", na qual o cantor gravou um de seus clipes, durante sua visita ao Brasil, em 1996.

Entretanto, o morro Dona Marta, como outros morros da cidade, não ficou livre da presença de traficantes. Durante um longo período, a comunidade esteve dominada pelo poder do tráfico de drogas, e a baixa atuação do Estado na região levou a população a viver em condições precárias. Em 2008, após quase 100 anos desde que as primeiras famílias começaram a ocupar o morro, o Dona Marta foi dominado pela polícia. A ocupação deu-se como parte de uma política de governo que visava à implantação da Unidade de Polícia Pacificadora (UPP), com a ideia de polícia da paz, que, ao manter a segurança e estimular a participação das pessoas da comunidade, pudesse promover políticas sociais voltadas para o desenvolvimento da comunidade e recuperação da cidadania para sua população (UPP RJ, 2011).

O setor turístico, potencial natural da região, em razão da vista privilegiada, teve suas oportunidades ampliadas após a possibilidade de livre acesso pelas vielas da comunidade. Vale ressaltar o programa Rio Top Tour (UPP SOCIAL, 2010), que teve início em 2010. Criado pela Secretaria de Estado de Turismo, Esporte e Lazer, em convênio com o Ministério do Turismo, o programa tem como objetivo estimular o turismo comunitário em comunidades pacificadas. Para tal, o programa conta com o mapeamento dos principais pontos turísticos da comunidade, a instalação de placas de sinalização turística bilíngue e quiosques de informações para os turistas. Conta, ainda, com a parceria do Investe Rio, que fornece financiamento para aqueles que querem investir no turismo na comunidade, e com o Sebrae, que fornece capacitação para empreendedores locais e cursos de iniciação no turismo para os moradores. Cabe ressaltar que os investimentos em atividades turísticas se dão, principalmente, devido à crença que se tem no potencial do turismo para levar ao desenvolvimento. No Brasil, as políticas públicas voltadas para 0 desenvolvimento de atividades turísticas possuem caráter de políticas de desenvolvimento e são fortalecidas devido à crença em seu potencial de contribuir para desenvolver o País (OLIVEIRA, 2001).

Com mais de um século de ocupação, a comunidade Santa Marta é, hoje, uma referência ao se falar de favela no Rio de Janeiro. Embora o passado da comunidade tenha sido marcado pelo domínio dos criminosos na região e pelo descaso do poder público, resultando em uma comunidade precária de infraestrutura e qualidade de vida para os moradores, a partir de 2008, um novo capítulo da história da comunidade começou a ser escrito, com a 
entrada do Estado por meio da UPP, abrindo espaço para o aumento de atividades turísticas na região e reacendendo a esperança da comunidade pela melhoria nas condições de vida da população local. A comunidade passou a ser visitada, principalmente por turistas estrangeiros, que realizam visitas guiadas pelos seus principais pontos turísticos.

\section{0 Turismo na Comunidade Santa Marta à Luz da Gestão Social}

A análise a seguir deu-se com base nas categorias e critérios propostos por Tenório et al. (2008), conforme apresentado na Tabela 1. Foi identificada, na fala dos entrevistados, a forma como essas categorias se mostraram presentes.

\subsection{A inclusão no desenvolvimento de atividades turísticas na comunidade Santa Marta}

A inclusão no desenvolvimento de atividades turísticas na comunidade Santa Marta foi analisada com base em três critérios, conforme exposto anteriormente: abertura dos espaços de decisão, aceitação social, política e técnica e valorização cidadã.

Apesar da importância da atividade turística na comunidade Santa Marta, diante das contribuições que pode trazer para a população local, quando perguntado se existe algum espaço para debate sobre o turismo na comunidade, geralmente a resposta dos moradores foi negativa. Alguns, entretanto, apontaram a proposta de reuniões pelo governo, para que as atividades turísticas na comunidade fossem discutidas. Mas, mesmo nesses casos, foram identificados impedimentos para a participação social, como a falta de espaço para os moradores se colocarem ou o horário inadequado das reuniões, fatores que levaram ao esvaziamento dessas reuniões, não obstante o interesse inicial que esses supostos espaços de discussão despertaram nos moradores. Esse fato é explicitado na fala de uma moradora:

as reuniões enchiam porque as pessoas também estavam insatisfeitas, mas não tinham o espaço para se colocarem, para conversar, para debater. [...] O governo já tinha uma ideia pronta, preparada para o turismo aqui dentro, e que não incluía a gente. [...] Ela aparece uma vez por mês para dizer que marcou uma reunião e não vai ninguém na reunião. [...] Três horas da tarde, a reunião na sexta-feira! (ENTREVISTADO 3 - mulher, guia de turismo e moradora).

Boullosa e Schommer (2010) destacam a importância de que o Estado reveja a sua posição de primazia na condução de processos de transformação social, para que a gestão social se dê de maneira participativa. $O$ fato de o governo se apresentar com uma "ideia pronta" para o turismo na comunidade não atende ao estabelecimento de uma nova relação entre Estado e sociedade, requerida pela gestão social.

O mesmo desconhecimento que os moradores apresentaram em relação às reuniões propostas pelo governo também se mostrou presente no que diz respeito ao projeto Rio Top Tour. Os moradores entrevistados, em geral, responderam negativamente quando perguntados a respeito do conhecimento da existência do projeto ou, ao menos, demonstraram desconhecimento a respeito da proposta do projeto.Segundo um morador da comunidade: "Não tem conhecimento. Não tem porque não foi bem informado" (ENTREVISTADO 16 - homem, liderança e morador). Até mesmo 
um guia envolvido no projeto concorda com a falta de divulgação para a comunidade local: "[...] ninguém sabe do Rio Top Tour... [...] Teve alguma divulgação, o Rio Top Tour? Não houve nada." (ENTREVISTADO 1 homem, sócio de agência de turismo e não morador).

Desdeoseuplanejamento, oprograma é criticado pelos moradores, principalmente por aqueles que já trabalhavam com turismo na região e não foram consultados no que diz respeito à elaboração do programa. Uma moradora, muito atuante na atividade turística da comunidade, queixa-se: "eles fazem um plano de turismo aqui e as pessoas me conhecem, [...] fui pioneira nessa coisa de turismo mesmo, [...] E, pô, as pessoas não chamam você, entendeu?" (ENTREVISTADO 3 - mulher, guia de turismo e moradora).

Para que o processo se caracterize verdadeiramente como uma gestão social, Tenório (2008) chama atenção para a importância de um gerenciamento participativo e dialógico, no qual o processo decisório é exercido por meio de diferentes sujeitos sociais. Importantes decisões referentes ao desenvolvimento de atividades turísticas na comunidade Santa Marta, tomadas na etapa de planejamento do programa Rio Top Tour, segundo os moradores entrevistados, não contaram com a presença de atores muito importantes: os membros da comunidade.

O projeto Rio Top Tour contou, também, com a oferta de cursos para formação de guias de turismo, para que membros da comunidade pudessem se aperfeiçoar e se tornar habilitados a atuar na profissão. Entretanto, os cursos também não eram do conhecimento de todos, e a visão dos moradores que os conheciam não era, em geral, positiva. Uma moradora, por exemplo, ao ser indagada a respeito de sua opinião sobre os cursos oferecidos pelo programa Rio Top Tour, afirma:

Uma palhaçada! [...] É um desastre, porque eles não prepararam a comunidade, vêm com os cursos em uns horários, com umas coisas que não tem nada a ver com a gente. Os cursos, as coisas não são feitas em cima da necessidade do morador, é em cima do que o governo acha legal de implantar aqui, e eles implantam. (ENTREVISTADO 3 mulher, guia de turismo e moradora).

Ao responder a essa mesma pergunta, outro morador concorda: "Não achei boa e acho que esse curso só veio para [...] falar que o morador também participa, mas é falta a inclusão do morador no turismo (ENTREVISTADO 4 - homem, estudante e morador).

Uma importante via de abertura de espaço de decisão e participação para os moradores da comunidade é sua atuação como guias de turismo. Embora os moradores tenham demonstrado interesse em se inserir nas atividades turísticas por meio da profissão de guia, essa entrada, segundo os relatos, parece ser dificultada, a começar pelas barreiras encontradas no curso de formação. Esse fato também se evidenciou na fala dos próprios agentes de turismo, como pode ser observado no seguinte relato:

Porque todo mundo, até no Santa Marta, pergunta: "Mas por que você não usa a gente como monitor dos seus passeios?". "Gostaria muito, mas eu não sei se vocês falam inglês." [...] eu já tenho um guia dentro do carro, não tem muito o que fazer. (ENTREVISTADO 1 homem, sócio de agência de turismo e não morador). 
Tenório (2008) chama atenção para o fato de que a gestão social, no contexto contemporâneo, tem se aproximado da gestão estratégica, pautando-se pela lógica do mercado, em detrimento de questões de natureza social. Isso pode ser observado na situação descrita acima, em que as exigências de qualificação advindas do mercado, bem como a lógica de eficiência, mostram-se presentes em uma situação em que a gestão social é requerida.

Diante da ausência da abertura de espaços de decisão e de discussão das atividades turísticas propostas pelo governo, os moradores organizaram-se e formaram seu próprio comitê, conforme expressa uma moradora: "por que que a gente fez o comitê, comitê de turismo do Santa Marta? [...] porque o governo veio aqui, começou a desenvolver um turismo da maneira que eles achavam legal" (ENTREVISTADO 3 - mulher, guia de turismo e moradora). Com base nas informações obtidas, pode-se especular que há, por parte dos moradores, o reconhecimento da necessidade de uma metodologia que possibilite sua inserção nesse processo, como pode ser observado na fala de uma moradora, que também atua como guia:

[...] infelizmente, a gente não foi preparado para essa realidade que existe aqui hoje dentro do Santa Marta. [...] As pessoas não sabem como se inserir nesse novo contexto que apareceu aqui no Santa Marta [...] Então, quando eles entraram com esse projeto, a gente não tinha capacitação, a gente não tinha nada! (ENTREVISTADO 3 - mulher, guia de turismo e moradora).

Entretanto, o mesmo reconhecimento não parece se fazer presente por parte do governo. Os relatos de alguns moradores parece demonstrar a ausência de preocupação por parte do poder público de inserir os membros da comunidade nesse novo processo:

[...] porque eles queriam fazer a sua promoção e a gente, que é protagonista aqui dentro, ficou de lado, a gente virou coadjuvante. O governo já tinha uma ideia pronta, preparada para o turismo aqui dentro e que não incluía a gente. (ENTREVISTADO 2 - mulher e moradora)

Os moradores relatam, ainda, uma aparente falta de investimento do governo nos membros da comunidade, para que sua inserção seja facilitada. Ao se referir ao investimento do governo nos moradores, para sua inserção nas atividades turísticas, uma moradora afirma: "Eu pensei que eles iam investir no morador. [...] E eu percebi que eles não tinham um investimento na gente" (ENTREVISTADO 21 - mulher, agente comunitária e moradora).

Oliveira, Cançado e Pereira (2010) destacam, como uma das três principais características da gestão social, a tomada de decisão coletiva, baseada no entendimento e na argumentação, sem que haja qualquer forma de coerção. Para que isso seja possível, é preciso o reconhecimento da necessidade de uma metodologia participativa, tanto por parte da sociedade quanto por parte do governo.

Mesmo diante das dificuldades expostas, os moradores parecem valorizar sua participação e considerá-la relevante, e apresentam uma série de argumentos que fundamentam essa importância. Um morador afirma, por exemplo, que "[...] quem conhece o morro é quem mora no morro, - pessoal sobe aí e não conhece nada" (ENTREVISTADO 14 - homem, locutor da rádio Santa Marta e morador), para justificar 
a importância da atuação dos moradores como guias de turismo locais. A importância da comunidade para a continuidade do projeto também foi destacada: " $E$ outra coisa: daqui a pouco eles vão embora, vai ter eleição, e esse povo não vai ficar aí para sempre, é a gente que tem que tocar essa atividade aqui dentro" (ENTREVISTADO 3 mulher, guia de turismo e moradora).

A relevância do resgate da identidade cultural é ressaltada, juntamente com a importância da inserção da comunidade nas atividades turísticas para tal. Esse aspecto se mostra presente, por exemplo, na fala de uma moradora: "A atividade turística tem muito a contribuir nesse sentido, não só de você resgatar a história do Santa Marta, como de todas as outras favelas. [...] é você consolidar a questão da identidade, a sua identidade [...]" (ENTREVISTADO 3 mulher, guia de turismo e moradora).

É central, na visão de Furtado (1984), a preservação de uma identidade cultural, para que o processo de desenvolvimento efetivamente ocorra. E essa preservação, como expressam os moradores da comunidade, só pode se dar por meio daqueles que são conhecedores de sua própria história. Também para Tenório (2008), as ações de desenvolvimento só terão eficácia se o poder público se colocar como apenas um dos agentes envolvidos e passar a levar em conta a cultura local, por meio da participação daqueles que melhor a conhecem: os membros da comunidade.

\subsection{O pluralismo no desenvolvimento de atividades turísticas na comunidade Santa Marta}

O pluralismo, entendido como a diversidade de atores envolvidos no processo de desenvolvimento de atividades turísticas na comunidade Santa Marta, foi analisado por meio de dois critérios: participação de diferentes atores e perfil dos atores.

A participação de diferentes atores pode ser evidenciada na fala dos entrevistados. Houve uma tentativa de inserir os moradores, importantes atores do processo, nas atividades turísticas, principalmente por meio da Associação de Moradores, como aparece no relato de um dos guias de turismo:

Teve o Zé Mário, que é o presidente da associação. A primeira reunião foi com ele, [...] Aí eu fiz um "fun trip" com todas as agências de turismo, marquei com todo mundo que vende, chamei o Zé Mário, para o Zé Mário ir, para ele conhecer, para as pessoas conhecerem o Zé Mário, enfim, trabalhinho de formiguinha, as pessoas comprando o produto (ENTREVISTADO 1 - homem, sócio de agência de turismo e não morador).

É importante destacar que houve tentativas de envolver os moradores nas atividades turísticas da comunidade, por meio dos cursos de formação oferecidos pelo programa Rio Top Tour. Entretanto, como já foi destacado, o curso não teve uma boa receptividade por parte dos moradores, e os membros da comunidade ainda enfrentam dificuldades, principalmente no que diz respeito à qualificação profissional, para se consolidarem como guias de turismo dentro de Santa Marta.

Tendo em vista que a iniciativa do Projeto Rio Top Tour partiu do governo, diante da oportunidade que enxergou com a pacificação, o poder público também foi envolvido no processo de desenvolvimento da atividade turística na comunidade Santa Marta, como pode ser observado por meio do relato de um guia de turismo que recebeu uma demanda do governo para atuar na comunidade: 
[...] quando entrou a UPP, há três, quatro anos atrás, no Santa Marta, acho que foi mais ou menos isso, logo depois, o Secretário de Turismo me chamou, o Antônio Pedro. E aí, se eu não me engano, foi assim: "Implementamos a UPP, agora cada um tem uma função para ser implementada, o prefeito, o governador... Mas cada Ministério tem a sua, cada secretaria tem a sua função de implementar alguma coisa positiva lá dentro" (ENTREVISTADO 1 - homem, sócio de agência de turismo e não morador).

Dado que o incentivo do turismo na região está relacionado à pacificação, como revela o relato acima, os policiais que atuam na UPP da Santa Marta foram também envolvidos no processo, ainda que não de modo contínuo e organizado. A atuação dos policiais em atividades relacionadas ao turismo evidenciase na fala de alguns entrevistados:

Na época do Rio Top Tour, lógico que a gente participou junto à Secretaria de Turismo, Esporte e Lazer e tudo mais, a gente, não é? Conversou bastante, a gente ajudou a escolher alguns pontos, ajudou aí a sinalizar, [...] Então, a gente ajudou. [...] O que acontece às vezes é: eu estou saindo aqui, está o guia chegando, aí eles param, conversam, perguntam, mas, assim, nada que... Ah, uma rotina. (ENTREVISTADO 6 - homem, policial UPP e não morador).

Um importante ator desse processo, o guia de turismo, em geral, vem de fora da comunidade. Ao serem perguntados sobre o enfrentamento de resistência por parte dos moradores, os guias responderam de maneira negativa: "Não, não, eles acham legal, falam que eu estou em todas, mas realmente eu estou mesmo, onde tem um espaço eu estou, mas é uma coisa minha [...]" (ENTREVISTADO
9 - homem, guia de turismo). Ainda assim, os guias não parecem ter problemas quanto à receptividade dos moradores, inserindo-se nas atividades turísticas da comunidade com facilidade. Mesmo aqueles que são guias externos têm essa mesma percepção: "Não, eu não senti resistência [...]" (ENTREVISTADO 12 - homem, guia de turismo independente e não morador).

Embora haja atuação de diferentes atores no desenvolvimento das atividades turísticas do Santa Marta, o perfil deles não parece ser marcado por uma característica de ativa participação e integração. Os guias de turismo, por exemplo, parecem ter uma preocupação maior em passar despercebidos do que em realmente se inserir na comunidade de maneira ativa. Um deles afirma: "A gente, quando entra na favela, a gente tenta ser o menos impactante possível. E cabe o bom senso. [...] Então, a ideia é passar com 200 pessoas despercebido" (ENTREVISTADO 1 - homem, sócio de agência de turismo e não morador).

Da parte dos moradores, por outro lado, houve demonstrações de preocupação e valorização da participação da comunidade, revelando um perfil caracterizado pela vontade de se inserir em processos democráticos. Essa preocupação evidencia-se na fala de alguns moradores, como revela o fragmento a seguir:

Inclusive eu procuro mostrar para as pessoas e dizer para as pessoas que elas têm que "estar acompanhando" a evolução da comunidade porque senão elas não vão ter condição "de estar morando" aqui [...] Seria supostamente uma "expulsão branca", não é? [...] (ENTREVISTADO 20 - homem, liderança e morador) 
Os policias que atuam na UPP da comunidade, por sua vez, também demonstraram um perfil de indivíduos interessados em se inserir no processo. A importância da participação foi enfatizada por alguns policiais: "Isso porque é mister que a gente tenha participação, para ver e ter conhecimento do que está acontecendo na comunidade." (ENTREVISTADO 15 homem, policial UPP e não morador).

A gestão social, orientada pela racionalidade comunicativa proposta por Habermas (2002), dá-se, segundo Tenório (2008), por meio de um acordo alcançado comunicativamente entre os diferentes atores. É nesse sentido que o envolvimento desses atores nas atividades turísticas se faz necessário, para que estes possam se aproximar da gestão social das atividades turísticas em busca do desenvolvimento.

\subsection{O bem comum no desenvolvimento de atividades turísticas na comunidade Santa Marta}

O bem comum, relacionado ao alcance do bem-estar social, foi analisado por meio de dois critérios: os objetivos alcançados e a aprovação cidadã dos resultados.

O objetivo maior, por trás do incentivo de atividades turísticas na comunidade Santa Marta, diz respeito, principalmente, ao desenvolvimento da comunidade. Um espaço marcado por precariedade, falta de infraestrutura e instabilidade, a comunidade conta, agora, com o turismo como uma forma de mudar esse cenário, não apenas pela geração de renda mas também por meio do atendimento das necessidades humanas, ambos os conceitos relacionados à noção de desenvolvimento (FURTADO, 2000).

Os moradores entrevistados ressaltaram a geração de renda como um dos principais benefícios trazidos pelo aumento das atividades turísticas na comunidade. $O$ aumento da renda foi destacado, assim, como o principal ganho da comunidade: "Acho que o ponto positivo, eu acho que é a geração de renda, não é?" (ENTREVISTADO 4 - homem, estudante e morador). O favorecimento financeiro predominou nas respostas à pergunta sobre os pontos positivos do turismo para a comunidade: "Está favorecendo muito a comunidade [...] financeiramente. Porque o comércio da comunidade está sendo mais valorizado" (ENTREVISTADO 2 - mulher e moradora).

O benefício trazido para os comerciantes da comunidade Santa Marta foi destacado pelos entrevistados, como revela uma moradora que desempenha atividades comerciais na comunidade: "Pra nós, comerciantes, não é? Gera aquela renda maior, não é? [...] Quem tem seu comércio aberto, eles sobem muito [...] Fazem lá a sua visita técnica e acabam parando sempre em alguma barraquinha" (ENTREVISTADO 18 - mulher, comerciante e moradora).

Entretanto, também houve reclamações por parte de moradores e comerciantes, em relação a algumas características dos turistas, que limitam a geração de renda. Um ponto de destaque éa barreira que os turistas apresentam em relação ao consumo de alimentos e bebidas, por, provavelmente, duvidarem da higiene de alimentos provenientes da comunidade. Um morador, que também vende suas pinturas na comunidade, ressalta essa insatisfação:

Não ache você que eles vêm aqui ou vão direto à minha venda. Não altera nada. Não vende nada. Não adianta. Até sorvete Kibon, que é pasteurizado... Eles não compram. [...] Biscoito, eles trazem tudo da rua, água mineral, porque lá no país deles a água lá é constante. Eles não autorizam... É decepcionante. [...] É 
cultural... [...] (ENTREVISTADO 7 - homem, artista plástico e morador).

Outra queixa que se destacou foi o baixo gasto dos turistas, associado pelos moradores à preocupação em poupar. Nesse sentido, eles foram caracterizados como avarentos pelos moradores: "Eles estão, assim, muito "pãoduros" no sentido de comprar. Por mim, eles compram muito pouco" (ENTREVISTADO 8 homem, membro de ONG e morador).

$O$ atendimento das necessidades humanas, entretanto, não foi ressaltado por nenhum dos entrevistados. Ainda que tenham sido questionados a respeito dos benefícios que o turismo tem trazido para a comunidade, melhorias sociais não foram destacadas. Mencionaram-se apenas as financeiras. As características de precariedade e de baixo atendimento das demandas sociais, que dão identidade às comunidades cariocas, conforme mostrou Maricato (2001), mostraramse presentes na fala dos entrevistados como marcas que ainda fazem parte do cotidiano dos moradores. Um dos membros da comunidade revelou, por exemplo, a falta de investimentos sociais:

E outra coisa não é a favor, o governo a todo momento diz que superou a arrecadação. "Olha, nesse mês arrecadou 30 bilhões". Cadê esses bilhões? A educação é um lixo! A saúde é outro lixo! [...] Então só com consciência cidadã, mobilização [...] (ENTREVISTADO 14 - homem, locutor da rádio Santa Marta e morador).

O problema do lixo também apareceu nas entrevistas como aspecto que prejudica a atividade turística e que é marcante no dia a dia dos moradores da comunidade Santa Marta: "Eu já vi reclamação de turista falando: 'Ah, porque aquele beco ali está sujo e tal', não é? [...]" (ENTREVISTADO 18 - mulher, comerciante e moradora).

A fala dos moradores entrevistados parece indicar que a aprovação cidadã dos resultados obtidos até então, a partir do desenvolvimento das atividades turísticas no caso estudado, de modo geral, não é positiva.Ao serem questionados a respeito do impacto do turismo na comunidade, alguns moradores destacaram que essas atividades ainda não trouxeram melhorias visíveis: "Eu gostaria que alterasse, mas realmente não tem impacto. Eles entram, saem, sem deixar nenhum lucro" (ENTREVISTADO 16 - homem, liderança e morador). Nesse mesmo sentido, outro morador brinca:

É igual à coisa da azeitona, não serve para nada. Já viu azeitona? Não serve para nada. Não altera nada. Eles são frios. É natural, são de país frio, europeu. [...] Eles não fomentam a vida, eles não incrementam. (ENTREVISTADO 7 homem, artista plástico e morador).

$E$, nos casos em que os resultados do turismo foram aprovados, o que se destacou foi, mais uma vez, o benefício financeiro por ele trazido. $O$ fragmento a seguir revela esse aspecto: "No momento está favorecendo muito a comunidade. Entendeu? "Verbamente", financeiramente... Porque o comércio da comunidade está sendo mais valorizado" (ENTREVISTADO 2 - mulher e moradora).

Ao definir desenvolvimento a partir de uma perspectiva mais ampla, que envolve aspectos econômicos, mas também sociais, Furtado (2000, p. 22) lembra que "o aumento da eficácia do sistema de produção - comumente apresentada como indicador principal do desenvolvimento - não é condição suficiente para que sejam mais 
bem satisfeitas as necessidades elementares da população". Da mesma forma, na visão do autor, a elevação dos padrões de vida e 0 atendimento das necessidades humanas podem se dar na ausência de um aumento da eficácia do sistema de produção. Nesse sentido, o destaque para a geração de renda com as atividades turísticas, aspecto que predominou na fala dos entrevistados, deve ser tratado com cautela, já que, como, há muito, os teóricos do desenvolvimento já destacaram, crescimento econômico não é sinônimo de desenvolvimento e, como avança Furtado (1984), não é, nem mesmo, uma condição necessária para tal.

\section{Conclusão}

Ao se analisar o desenvolvimento de atividades turísticas em uma comunidade pacificada, na perspectiva da gestão social, conforme 0 objetivo proposto, pode-se observar, por meio da fala de moradores, guias de turismo e policiais inseridos na comunidade, que, no caso estudado, parece não haver espaços de discussões formais que tenham uma abertura real para ouvir a comunidade, o que levou os moradores a formarem seu próprio comitê de turismo. A inserção dos moradores como guias de turismo parece ser dificultada, principalmente, pela falta de capacitação, e o curso oferecido pelo governo para solucionar tal problema não parece ter uma boa receptividade. Mesmo diante dessas dificuldades, a valorização pelos membros da comunidade da importância de sua participação, em geral, mostra-se presente na fala dos moradores. Ainda que muitos atores entre moradores, policias, agentes de turismo ou poder público - estejam envolvidos nas atividades turísticas da comunidade, apenas os membros da comunidade parecem possuir uma real vontade de se inserir e de se envolver, sem tentar apenas "passar despercebidos".
Os resultados obtidos por meio do turismo na comunidade Santa Marta também não pareceram ter atingido os objetivos propostos. Algumas conquistas foram alcançadas, no que se refere aos aspectos econômicos, como o aumento do comércio e da demanda pelo serviço de guia de turismo. As necessidades humanas dos moradores, entretanto, não parecem ter sido atendidas. Relatos de problemas de lixo, saúde ou falta de infraestrutura foram ressaltados nas falas dos entrevistados. Como consequência, os moradores, em geral, demonstram não acreditar que houve um impacto positivo do turismo na comunidade.

Holanda e Vieira (2003) explicam que, quando as comunidades locais acham-se marginalizadas e não conseguem participar do desenvolvimento das atividades turísticas, os benefícios trazidos para a comunidade resumemse, no máximo, aos de viés econômico. Esse fenômeno pode ser observado na comunidade Santa Marta. Os poucos benefícios decorrentes do turismo, mencionados nas entrevistas, dizem respeito a questões de âmbito econômico. Isso se mostra presente na fala de todos os atores envolvidos, desde os comerciantes, que exaltam os benefícios da aceleração de atividades comerciais, aos guias de turismo internos e externos, que comemoram o aumento da demanda por seu produto.

O crescimento econômico é, porém, insuficiente para a geração de transformações sociais mais amplas, as quais também são abarcadas pelo conceito de desenvolvimento, conforme mostrou Furtado (2000). Para que mudanças ocorram também em seus aspectos substantivos, a inclusão dos atores, verdadeiramente dispostos a se integrar, por meio de espaços de discussão que funcionem de maneira organizada, faz-se necessária.

O cenário observado é, assim, reflexo da difícil inserção social no processo de desenvolvimento das atividades turística na 
comunidade Santa Marta. Entretanto, para além do crescimento da "indústria turística", é importante a promoção do desenvolvimento local (HOLANDA; VIEIRA, 2003), o que só pode ser obtido com a participação da comunidade, com a compreensão do homem como cidadão. É nesse sentido que a gestão social se apresenta como uma possibilidade de superação da falaciosa relação direta entre turismo e desenvolvimento local, e se faz necessária para que se tenha no cidadão o verdadeiro beneficiado.

\section{Referências}

BATISTA, G. M. Turismo e desenvolvimento local: uma alternativa para as comunidades brasileiras. In: Encontro Nacional de Empreendedorismo, 5, Brasília, Anais... Brasíia, UEM/UEL/UnB, 2003.

BOISIER, S. Desarrollo (local): ¿ de qué estamos hablando? Estudios Sociales, v. 103, Santiago, CPU, 2000.

BOULLOSA, R. F.; SCHOMMER, P. C. Gestão social: caso de inovação em políticas públicas ou mais um enigma de Lampedusa? In: RIGO et al. Gestão social e políticas públicas de desenvolvimento: ações, articulações e agendas. Recife: Univasf, 2010.

BUARQUE, S. C. Construindo o desenvolvimento local sustentável. Rio de Janeiro: Garamond, 2002.

COSTA, V. G.; NASCIMENTO, J. A. S. O conceito de favelas e assemelhados sob o olhar do IBGE, das prefeituras do Brasil e da ONU. In: Encontro de Geógrafos da América Latina, 10, São Paulo, 2005. Anais. São Paulo, 2005.

CUNHA, L. Economia e política do turismo. Lisboa: McGraw-Hill, 1997.
DENALDI, R. Intervenção municipal em favelas: aprimoramento e limitações. In: Encontro Nacional da Associação Nacional de Pósgraduação e Pesquisa em Planejamento Urbano e Regional, 11, ANPUR, Anais. Salvador, 2005.

FARIA, V. M.; DIAS, A. F. Microrregião de Lavras (MG). In: TENÓRIO, F. G. (Org.). Cidadania e desenvolvimento local: critérios de análise. Rio de Janeiro: FGV, 2012. v. 1.

FURTADO,C.Introduçãoaodesenvolvimento: enfoque histórico-estrutural. 3. ed. Rio de Janeiro: Paz e Terra, 2000.

FURTADO, C.. Cultura e desenvolvimento em época de crise. Rio de Janeiro: Paz e Terra, 1984.

FREITAG, B.. A teoria crítica, ontem e hoje. Brasiliense, 1986.

GODOY, K. E.; LUNA, Sarah Borges. A estética turística e cinematográfica da favela: suportes de uma autenticidade construída. Caderno Virtual de Turismo, Rio de Janeiro, v. 12, n. 2, p. 239-252, 2012.

\section{HABERMAS, J. Agir comunicativo e razão} destranscendentalizada. Rio de Janeiro: Tempo Brasileiro, 2002.

HOLANDA, L. A.; VIEIRA, M. M. F. Sobre a falácia da relação direta entre turismo e desenvolvimento local. In: CARVALHO, C. A.; VIEIRA, M. M. F. Organizações, cultura e desenvolvimento local: a agenda de pesquisa do observatório da Realidade Organizacional. Recife: Edufepe, 2003.

IBGE. Economia do turismo: uma perspectiva macroeconômica. Rio de Janeiro, 2010. 
Disponível em: <http://www.ibge.gov.br/home/ estatistica/economia/industria/economia_ tur_20032007/publ_comp_ecotur.pdf>. Acesso em: 18 abr. 2012.

LAGE, B. H. G.; MILONE, P. C. (Orgs.). Turismo: teoria e prática. São Paulo: Atlas, 2000.

MARICATO, E. Favelas: um universo gigantesco e desconhecido. 2001. Disponível em: <http:// www.usp.br/fau/depprojeto/labhab>. Acesso em: 19 jan. 2012.

MARTINS, P. E. M. A reinvenção do sertão: a estratégia organizacional de Canudos. Rio de Janeiro: FGV, 2001.

MARTINS, S. R. O. Desenvolvimento local: questões conceituais e metodológicas. Revista Internacional de Desenvolvimento Local, v. 3, n. 5, p. 51-59, set. 2002.

MELO, W. S. Microrregião de Garanhus (PE). In: TENÓRIO, F. G. (Org.). Cidadania e desenvolvimento local: critérios de análise. Rio de Janeiro: FGV, 2012. v. 1.

MEDEIROS, B. F. A construção da favela carioca como destino turístico. Rio de Janeiro: CPDOC, 2006.

MEDEIROS, B. F. Entre tapas e beijos: a favela turística na perspectiva de seus moradores. Revista Sociedade e Estado, v. 25, n. 1, jan./ abr. 2010.

MEDEIROS, B. F. Gringo na laje: produção, circulação e consumo da favela turística. Rio de Janeiro: FGV, 2009.

MEDEIROS, B. F. A favela que se vê e que se vende: reflexões e polêmicas em torno de um destino turístico. Revista Brasileira de
Ciências Sociais, v. 22, n. 65, 2007.

MENEZES, P. Turismo e favela: reflexões sobre ética e fotografia. Dialogando no Turismo, Rosana, v. 1, n. 3, p. 10-30, 2007.

MINISTÉRIO DO TURISMO. Estatísticas básicas de turismo. Brasília, 2011.

MORAES, C. Turismo e o Museu de Favela: um caminho para novas imagens das favelas do Rio de Janeiro. Revista Eletrônica de Turismo Cultural, São Paulo, v. 7, 2010.

OLIVEIRA, A. P. Turismo e desenvolvimento: planejamento e organização. 3. ed. rev. e ampl. São Paulo: Atlas, 2001.

OLIVEIRA, J. S. Repensando a questão das favelas. Revista Brasileira de Estudo de População, Campinas, v. 2, n. 1, p. 9-30, jan./jun. 1985.

OLIVEIRA, V.A. R.; CANÇADO, A. C.; PEREIRA, J. R.. Gestão social e esfera pública: aproximações teórico-conceituais. CADERNOS EBAPE. BR, v. 8, no 4, artigo 3, Rio de Janeiro, Dez. 2010.

PINHO, J. A. G. Gestão social: conceituando e discutindo os limites e possibilidades reais na sociedade brasileira. In: RIGO et al. Gestão social e políticas públicas de desenvolvimento: ações, articulações e agendas. Recife: Univasf, 2010.

SACHS, I. Desenvolvimento e cultura. Desenvolvimento da cultura. Cultura do desenvolvimento. Organizações \& Sociedade, v. 12 , n. 33, p. 151-162, abr./jun. 2005.

SERSON, P.; PIRES, M. J. A experiência turística na Favela da Rocinha (Rio de Janeiro - RJ). Revista Eletrônica de Turismo Cultural, São 
Paulo, v. 4, 2008.

SOUSA, L. S. Turismo e desenvolvimento local sustentável na Paraíba. 2006. Disponível em: <http://www.eumed.net/libros/2006b/lss/index. htm>. Acesso em: 18 abr. 2012.

TENÓRIO, F. G. Tem razão a administração? In: TENÓRIO, F. G. Tem razão a administração? Ensaios de teoria organizacional e gestão social. ljuí: Unijuí, 2002.

TENÓRIO, F. G. Cidadania e desenvolvimento local. Rio de Janeiro: FGV; ljuí: Unijuí, 2007.

TENÓRIO, F. G. Um espectro ronda o terceiro setor, o espectro do mercado: ensaios de gestão social. 3. ed. ljuí: Unijuí, 2008.

TENÓRIO, F. G. et al. Critérios para a avaliação de processos decisórios participativos deliberativos na implementação de políticas públicas. In: III Encontro de Administração Pública e Governança, Anais... Salvador, 2008.

UPP RJ. Conceito de UPP: a polícia da paz. 2011.
Disponível em: <http://upprj.com/wp/?page $\mathrm{id}=20$. . Acesso em: 9 nov. 2011.

UPP SOCIAL. Favela top tour. 2010. Disponível em: <http://www.uppsocial.com.br/favela-toptour>. Acesso em: 17 abr. 2012.

VALLADARES, L. A gênese da favela carioca: a produção anterior às ciências sociais. Revista Brasileira de Ciências Sociais, v. 15, n. 44, outubro, 2000.

VALLADARES, L.; FIGUEIREDO, A.. Housing in Brazil: na introduction to recent literature. Bulletin of Latin American Research, v. 2, n. 2, p. 69 - 91, may., 1983.

VILLELA, L. E. Escopo metodológico. In: TENÓRIO, F. G. (Org.). Cidadania e desenvolvimento local: critérios de análise. Rio de Janeiro: FGV, 2012. v. 1.

VIZEU, F. Ação comunicativa e estudos organizacionais. Revista de Administração de Empresas, v. 45, n. 4, out./dez. 2005. 